\title{
Donor and surgical risk factors for primary graft failure following Descemet's stripping automated endothelial keratoplasty in Asian eyes
}

This article was published in the following Dove Press journal:

Clinical Ophthalmology

I4 October 2011

Number of times this article has been viewed

\author{
Marcus Ang ${ }^{1,2}$ \\ Hla M Htoon ${ }^{1,2}$ \\ Howard Y Cajucom-Uy ${ }^{1,2}$ \\ Donald Tan ${ }^{1-3}$ \\ Jodhbir S Mehtal-4 \\ 'Singapore National Eye Centre, \\ Bukit Merah, ${ }^{2}$ Singapore Eye Research \\ Institute, Bukit Merah, ${ }^{3}$ Department of \\ Ophthalmology, Yong Yoo Lin School \\ of Medicine, National University of \\ Singapore, Queenstown, ${ }^{4}$ Duke-NUS \\ Graduate Medical School, Outram, \\ Singapore
}

Correspondence: Jodhbir S Mehta Singapore National Eye Centre, II Third Hospital Avenue, Singapore 16875I

Tel +6562277255

Fax +6562277290

Email jodmehta@gmail.com
Background: Descemet's stripping automated endothelial keratoplasty (DSAEK) has been shown to have superior refractive and visual results compared with penetrating keratoplasty, but higher rates of primary graft failure (PGF). This paper presents donor and surgical risk factors for PGF in DSAEK cases in Asian eyes.

Design: Retrospective case-control study.

Participants: All consecutive patients who underwent DSAEK at a tertiary referral teaching hospital from March 2006-December 2008.

Methods: Donor details analyzed were: age of donor, cause of donor death, death to harvesting time, donor storage time, distribution distance of tissue, preoperative endothelial cell count. Surgical factors analyzed were: donor diameter, donor thickness, and method of donor insertion. These risk factors in cases of PGF were compared with patients with successful DSAEK as the control group.

Main outcome measure: PGF.

Results: A total of 124 DSAEK procedures were performed. Six DSAEK procedures (five eyes of five patients; one eye with two failures) resulted in PGF (4.8\%). Significant risk factors were found for PGF to include graft insertion using a folding technique (odds ratio [OR], 34.03; 95\% confidence interval $[\mathrm{CI}], 3.75-314.32 ; P=0.0017)$ and a small donor diameter $(\mathrm{OR}, 39.94$; 95\% CI, 2.18-732.17; $P=0.013)$.

Conclusion: The results of this study suggest that in Asian eyes with shallow anterior chambers, surgical trauma relating to the technique of donor insertion, and the use of a small donor are major risk factors for PGF following DSAEK.

Keywords: DSAEK, PGF, penetrating keratoplasty

\section{Introduction}

Primary graft failure (PGF) refers to failure of the graft to clear after surgery, with persistent graft edema relating to endothelial damage or dysfunction. ${ }^{1}$ There are no clearly defined risk factors in the majority of cases, but postulated etiologies which have been associated with PGF in penetrating keratoplasty (PK) include donor factors such as trauma as a cause of donor death, donor age $>70$ years, prolonged death to preservation time or prolonged donor storage time, ${ }^{2}$ endothelial damage during donor retrieval or storage, ${ }^{3}$ and surgical factors relating to surgical technique and surgical trauma. ${ }^{4}$

Descemet's stripping automated endothelial keratoplasty (DSAEK) is a recent form of endothelial keratoplasty procedure in which Descemet's membrane and diseased endothelial tissue is replaced with a healthy partial thickness posterior donor lenticule. 
DSAEK is rapidly increasing in popularity as an alternative to conventional PK due to inherent advantages of small incision, closed-globe, sutureless surgery, resulting in enhanced structural integrity and more rapid visual recovery relating to minimal refractive change and the lack of graft sutures. ${ }^{5}$ However, folding and grasping of the donor tissue with forceps to enable insertion through a small incision, intraocular manipulation to unfold the donor, the use of intraocular air to enable adhesion of the donor to the posterior stromal surface, and a significant learning curve, all potentially increase the risk of endothelial damage. Recent reports have suggested that increased donor endothelial cell loss occurs during automated donor lamellar dissection and donor unfolding in the anterior chamber. ${ }^{6}$ While PGF following PK is uncommon (reported incidence $=2.1 \%),{ }^{1}$ it is the third most common reported complication following DSAEK (mean rate $=5.0 \%$; range $0 \%-29 \%){ }^{7}$ This is further supported by recent reports of higher endothelial cell loss at 6 months and 1 year after DSAEK, as compared with PK, which is related to more donor tissue manipulation in DSAEK. ${ }^{8,9}$

The authors of this present paper initiated a DSAEK surgical program at the Singapore National Eye Centre (SNEC), and graft failures occurring early in the series prompted the modification of the folding procedure of donor insertion to a pull-through glide technique. ${ }^{10}$ This suited the smaller Asian eye with shallower anterior chamber ${ }^{11}$ and higher vitreous pressure, which creates difficulties particularly with the unfolding of the donor in the anterior chamber.

A review of current literature revealed that while many papers have described PGF rates and postulated possible etiologies, none have formally assessed clinical or surgical risk factors. Likewise, the majority of reported series of DSAEK have been performed in Caucasian eyes with biometrically deeper anterior chambers than Asian (Chinese) eyes. ${ }^{11}$ The authors of this paper thus performed a retrospective case-control study to determine the donor and surgical risks for PGF in DSAEK for Asian eyes.

\section{Methods}

A retrospective case-control study was conducted of all consecutive patients who underwent DSAEK at SNEC from March 2006 to December 2008. These patients were identified from the SNEC prospective cornea transplantation database. All consecutive patients who had undergone DSAEK procedures during the study period, which were performed by the same surgeon (DT) using previously described "taco" folding or glide techniques using a modified Sheets glide (BD Visitec ${ }^{\mathrm{TM}}$, Beaver-Visitec International,
Waltham, MA) (see Figure 1) were included. ${ }^{12}$ The notes for information pertaining to indications for DSAEK surgery, patient demographics, and surgical details were reviewed. Donor details were obtained from the Singapore Eye Bank database, including information such as the age of the donor, cause of donor death, death to corneal harvesting time, donor storage time (procurement to transplantation), and distribution distance of tissue (donors were obtained either locally, or from international eye banks based in the USA). ${ }^{1}$ Donor and surgical risk factors with patients in the database that had undergone successful DSAEK were compared as the control group. Successful DSAEK was defined as clarity and thinning of the posterior lamellar graft with no residual corneal edema within 6 weeks following DSAEK; and grafts that had not dislocated and showed no increase in thickness in donor size on anterior-segment optical coherence tomography (ASOCT).

Statistical analysis was performed, comparing demographic and other variables separately. Cases of PGF were compared with the control corneas that had undergone a successful DSAEK procedure. Univariate results are presented in odds ratios (ORs) with 95\% confidence intervals (CIs). All $P$ values obtained were two-tailed, with a significance level of $P<0.05$. The protocol of the study adhered to the provisions of the Declaration of Helsinki and was approved by the institutional review board and local ethics committee of the Singapore National Eye Centre and Singapore Eye Research Institute. PGF was the main outcome measure. PGF was diagnosed based on the following criteria: (1) the presence of diffuse edema of the posterior

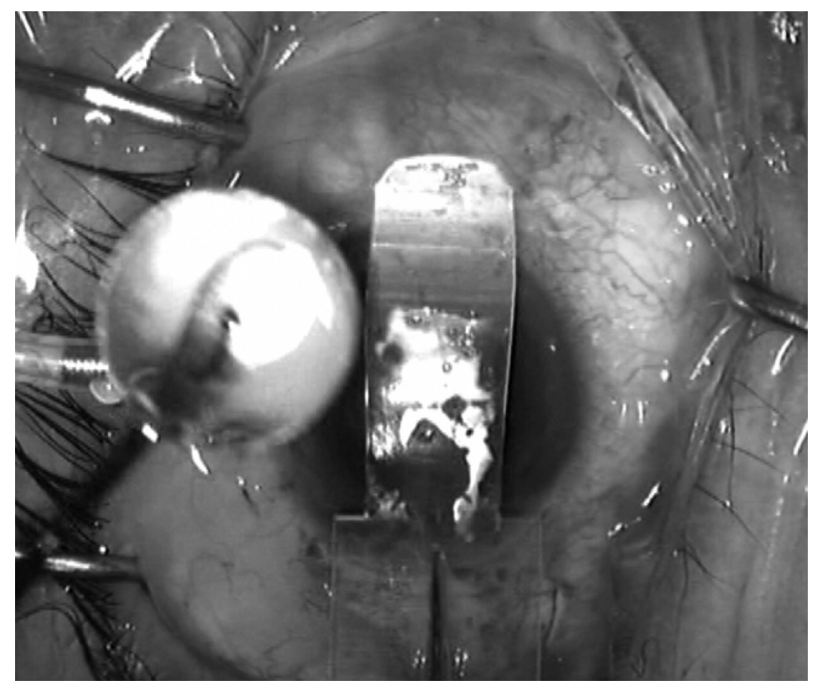

Figure I Intraoperative picture of modified Sheets glide (BD Visitec ${ }^{\mathrm{TM}}$, BeaverVisitec International, Waltham, MA) used in the glide insertion of donors for the study's DSAEK cases. 
lamellar and recipient corneal stroma apparent from the first postoperative day, (2) failure of the edema to clear spontaneously by 2 months, and (3) a lack of other peri- or postoperative risk factors such as donor dislocation (donor attachment was confirmed in all cases by ASOCT (Visante OCT, Carl Zeiss Meditec, Inc, Dublin, CA).

\section{Results}

A total of 124 DSAEK procedures were performed from March 2006 and December 2008. Six DSAEK procedures (five eyes of five patients; one eye with two failures) resulted in PGF, hence a total of six primary failures out of 124 DSAEK procedures (4.8\%). There were four females and one male patient. Preoperative diagnosis prior to graft exchange was bullous keratopathy in four patients and Fuchs endothelial corneal dystrophy in one patient. Operations were performed on three right eyes, and two left eyes. Mean pre-exchange pachymetry (on ASOCT) for recipient corneas was 772 ( \pm standard deviation 94) microns and $354 \pm 111$ microns for the donor lamellar. The mean time to graft exchange from primary procedure was $8 \pm 1$ weeks. The mean logarithm of minimum angle of resolution (logMAR) spectacle corrected visual acuity (SCVA) before graft exchange was $1.300 \pm 0.002$; compared with the mean $\log$ MAR SCVA of $0.4 \pm 0.07$ following exchange at 3 months post-operatively $(P=0.0002)$. All of the PGF cases had had posterior donor lamellar exchanges by a previously reported technique. ${ }^{10}$ One patient had this procedure performed twice.

The mean donor age for the cases of PGF was $50.0 \pm 16.3$ years compared with the mean age of the successful cases of $57.0 \pm 13.7$ years $(P=0.3)$. Four of the corneas that had PGF were donor mates. All corneas were preserved in Optisol GS ${ }^{\circledR}$ (Chiron Intraoptics, Irvine, CA). In this series, only one donor was precut from an eye bank in the US (which was not a case of PGF). Hence, no attempt was made to compare precut versus nonprecut tissue. The time from death to tissue recovery ranged from 1.5 hours to 24.5 hours. However, some of the donors were refrigerated prior to tissue recovery. The mean donor refrigeration time was $11.3 \pm 5.5$ hours. If the refrigeration time is subtracted from the total cadaver time in those cases, the overall mean cadaver time was $3.8 \pm 2.6$ hours. The mean cadaver time of the PGF cases without refrigeration time was $4.6 \pm 2.0$ hours, including the mean refrigeration time of $9.8 \pm 3.6$ hours. In comparison, the mean cadaver time of the successful cases without refrigeration time was $3.8 \pm 3.6$ hours $(P=0.39)$, with the mean refrigeration time $9.9 \pm 3.0$ hours $(P=0.5)$.
The overall mean storage time of the donor tissues was $5.0 \pm 1.8$ days (range, $2-7$ days). The mean storage time of the PGF cases was $5.8 \pm 1.4$ days compared with the mean storage time of the successful cases of $4.8 \pm 1.9$ days $(P=0.18)$. There was no significant difference between preoperative endothelial cell density (ECD) of the donors used in the successful cases and the cases with PGF $\left(2903 \pm 235\right.$ cells $/ \mathrm{mm}^{2}$ versus $2795 \pm 100$ cells $/ \mathrm{mm}^{2}, P=0.06$ ). Correlation analysis showed no association between cause of death and the age of the donor cornea or between age of donor and ECD; or ECD and donor storage time. There was no significant difference in the mean corneal donor thickness of the successful cases compared with those with PGF (203 \pm 51 microns versus $202 \pm 75$ microns, $P=0.55)$.

Table 1 illustrates the selected donor and surgical variables for cases of PGF with those of controls (successful DSAEK cases). Significant risk factors were found for PGF to include graft insertion using a folding technique (OR, 34.03; 95\% CI, 3.75-314.32; $P=0.0017$ ) and a small donor diameter (OR, 39.94; 95\% CI, 2.18-732.17; $P=0.013$ ). There was no significant difference between the two groups for the other risk factors, such as donor cadaver time ( $\geq 12$ hours), storage time ( $\geq 7$ days), source of tissue (local versus foreign), preoperative ECD ( $\geq 2801)$, donor age ( $\geq 71)$ cause of death (trauma), and thickness of donor posterior lamella $(\leq 250)$. On multivariate analysis, with technique $(P=0.066)$ and donor size $(P=0.997)$ controlling for each other, neither was significant.

\section{Discussion}

Endothelial damage with DSAEK surgery remains the major challenge to this new procedure, which is rapidly emerging as a popular alternative to PK surgery worldwide. When the DSAEK program was initiated at SNEC, it was noticed that there were not only difficulties with donor insertion but also unfolding the donor graft in a shallow anterior chamber, commonly seen in Asian Eyes, required increased manipulation of donor lenticule. ${ }^{11}$ This increased the risk of endothelial cell damage while performing DSAEK and thus possible greater risk of PGF. The mean rate of PGF following DSAEK in published literature is 5\% (range $=0 \%-29 \%),{ }^{7}$ which is similar to the initial PGF rate $(4.8 \%)$ in this present series. However, the authors of this present paper feel this rate to be unacceptably high, hence an attempt to evaluate causation in this study at this early stage in the program. All the tissues that were used in these present DSAEK cases would have been acceptable for standard PK and the rate for PGF in PK at SNEC is $1.7 \%$ (unpublished data), hence donor quality 
Table I Donor and surgical risk factors for primary graft failure

\begin{tabular}{|c|c|c|c|c|c|c|c|}
\hline \multirow[t]{2}{*}{ Parameters } & \multirow[t]{2}{*}{ Category } & \multicolumn{2}{|c|}{ Outcome (\%) } & \multirow[t]{2}{*}{ Odds ratio } & \multicolumn{2}{|c|}{$95 \%$ confidence interval } & \multirow{2}{*}{$\begin{array}{l}P \text {-value } \\
\text { ( } 2 \text { sided) }\end{array}$} \\
\hline & & Success $^{a}$ & Failure $^{b}$ & & Lower & Upper & \\
\hline \multirow[t]{2}{*}{ Donor source } & Foreign & $69(94.5)$ & $4(5.5)$ & 1.4 & 0.25 & 8.86 & 0.692 \\
\hline & Local & $49(96.1)$ & $2(3.9)$ & 1 & & & \\
\hline \multirow[t]{2}{*}{ Cadaver time, hours } & $<12$ & $63(9 \mid .3)$ & $6(8.7)$ & 3.26 & 0.12 & 88.37 & 0.483 \\
\hline & $\geq 12$ & $\mathrm{I}(100)$ & $0(0)$ & 1 & & & \\
\hline \multirow[t]{2}{*}{ Storage time, days } & $\leq 6.9$ & $52(94.5)$ & $3(5.5)$ & 0.23 & $0.04 I$ & 1.29 & 0.095 \\
\hline & $\geq 7$ & $12(80)$ & $3(20)$ & 1 & & & \\
\hline \multirow{2}{*}{$\begin{array}{l}\text { Donor endothelial cell count, } \\
\text { cells } / \mathrm{mm}^{2}\end{array}$} & $\leq 2800$ & $44(93.6)$ & $3(6.4)$ & 1.68 & 0.33 & 8.70 & 0.672 \\
\hline & $\geq 2801$ & $74(96.1)$ & $3(3.9)$ & 1 & & & \\
\hline \multirow[t]{2}{*}{ Donor age, years } & $\leq 70$ & $101(95.3)$ & $5(4.7)$ & 0.79 & 0.086 & 7.23 & 0.836 \\
\hline & $\geq 71$ & $16(94.1)$ & I (5.9) & 1 & & & \\
\hline \multirow[t]{2}{*}{ Cause of death } & Trauma & $19(86.4)$ & $3(13.6)$ & 5.2 & 0.007 & 27.80 & 0.053 \\
\hline & Others & $99(97.1)$ & $3(2.9)$ & 1 & & & \\
\hline \multirow[t]{2}{*}{ Insertion technique } & Fold & $15(75)$ & $5(25)$ & 34.03 & 3.75 & 314.32 & 0.0017 \\
\hline & Glide & $103(99)$ & $I(I)$ & I & & & \\
\hline \multirow[t]{2}{*}{ Donor diameter, $\mathrm{mm}$} & $\leq 8$ & $27(81.8)$ & $6(17.2)$ & 39.94 & 2.18 & 732.17 & 0.013 \\
\hline & $\geq 8.1$ & $84(100)$ & $0(0)$ & I & & & \\
\hline \multirow[t]{2}{*}{ Donor thickness, microns } & $\leq 250$ & $99(95.2)$ & $5(4.8)$ & 0.505 & 0.054 & 4.76 & 0.550 \\
\hline & $\geq 25$ I & $10(90.9)$ & I (9.1) & $\mathrm{I}$ & & & \\
\hline
\end{tabular}

Notes: a'Successful Descemet's stripping automated endothelial keratoplasty (DSAEK); ${ }^{\circ}$ primary graft failure.

selection was unlikely to be a factor. The rates for PGF in DSAEK are pertinent given the fact that DSAEK surgeons today are in fact requesting for, and utilizing, corneas with higher endothelial cell counts to perform this procedure. ${ }^{13}$

No significant effect of selected donor risk factors accounting for PGF in the cases of DSAEK in this present study was observed. The donor risk factors that were examined have been previously identified as proposed risk factors for PGF. ${ }^{1}$ These include donor age $>70$, trauma as a cause of death, a death to preservation time of over 12 hours, and a storage time of greater than 7 days. ${ }^{1}$ Once refrigeration time was excluded, none of the donor corneas used in this study had a death-to-preservation time of more than 12 hours. This study also looked at the effect of refrigeration of the donor prior to eye removal but no statistical difference was found in cases of PGF and controls whether the refrigeration time was included in the cadaver time or not.

Also included were other donor risk factors that may be pertinent to SNEC's local tissue requirement and many centers worldwide doing DSAEK that import tissue from overseas. Fifty percent of the donor tissue used at SNEC during this study came from the USA. Transportation of tissue overseas may have a detrimental effect on the endothelium, especially if there is excessive vibration. ${ }^{14}$ The results of this present study indicated that there were no detrimental effects on DSAEK outcomes comparing locally sourced and USA-sourced tissue. A trend to request tissue with higher endothelial cell count also prompted us to compare results of tissue with endothelial cell counts in excess of 2800 cells $/ \mathrm{mm}^{2}$; again there was no significant difference between controls and those with PGF. Terry et al also showed that there was no significant correlation between preoperative donor ECD and rates of dislocation in DSAEK; although their results were unable to show its relationship to PGF as compared with this present study. ${ }^{15}$ Due to the donor preservation methods used at SNEC and also in tissue sent from the USA (both Optisol GS), it was not possible to compare the effects of tissue storage, ie, organ culture or Optisol GS, on the rates of PGF. Likewise, the majority of the tissue was cut by microkeratome at the time of surgery (except for one case); hence the result of precut and perioperative cut tissue could not be compared with the results of PGF.

Despite ensuring similar donor quality in both PK and DSAEK, PGF rates relating to endothelial cell loss or damage are still higher in DSAEK. ${ }^{8}$ Price at al recently reported that at 1-year post-transplantation, although overall graft success was comparable for DSAEK and PK, the endothelial cell loss was greater with DSAEK. ${ }^{16}$ Recent histopathological studies have demonstrated endothelial attenuation (100\%), endothelial atrophy (75\%), and mild stromal inflammation (68\%) secondary to manipulation and surgical trauma in cases of PGF in DSAEK. ${ }^{17,18}$ Furthermore, in-vitro studies have shown that during the DSAEK procedure, endothelial cell trauma occurs at several stages. ${ }^{6}$ This study hence examined the effects of donor surgical factors, ie, donor diameter size, donor thickness, and donor insertion method, 
on the rates of PGF. Analysis showed that a smaller donor diameter $(\leq 8 \mathrm{~mm})$ and the folding technique were associated with PGF in this present series. The inference from this observation is that larger diameter grafts have less chance of failure. A graft of $9 \mathrm{~mm}$ diameter transfers $26 \%$ more surface area of endothelial cells than a graft of $8 \mathrm{~mm}$ in diameter. ${ }^{13}$ If the donor has a higher number of endothelial cells and the attrition rate is constant then there should be less chance of failure with larger grafts. Others have found that a larger incision leads to less donor lenticule manipulation; ${ }^{19}$ while the increased donor lenticule size confers more endothelial cell area, thus providing more cells to deturgesce a swollen cornea and less manipulation. ${ }^{18}$ It has also been suggested that larger donor lenticules suffer less manipulation due to better centration. ${ }^{20}$

Grafts of $9 \mathrm{~mm}$ are often used for DSAEK in results reported from the USA. ${ }^{7}$ However, in this present study, one of the problems noticed in the initial cases was that it was difficult to implant a donor of larger than $8 \mathrm{~mm}$ in diameter, since unfolding of the donor was very difficult in Asian eyes with shallow anterior chambers. It was often the case that the inferior wing of the folded graft would be unable to unfold because impediment by the iris would prevent extension of this part of the donor tissue. Recently, biometric data on a large sample of Asian eyes has shown that the mean anterior chamber depth is $2.68 \pm 0.3 \mathrm{~mm} .{ }^{11}$ If we presume that the donor tissue is folded in a standard 60:40 "taco," for a $9 \mathrm{~mm}$ graft, the anterior chamber depth would have to be a minimum of $3.6 \mathrm{~mm}$ to allow unfolding, without obstruction from the iris. The method of donor insertion in this study was therefore changed to a technique that doesn't involve folding or unfolding of the donor posterior lamellar. ${ }^{10}$ Analysis of donor insertion technique shows there is a significant risk of PGF with "taco" insertion compared with glide (OR, 34.03; 95\% CI, 3.75-314.32; $P=0.0017$ ) in Asian eyes. This is consistent with previous reports by Suh et al and Gorovoy et al, with difficulties in donor unfolding causing traumatic loss of endothelial cells. ${ }^{21,22}$ The present study did have one case of PGF following glide insertion. This was in a patient who developed a graft detachment in an excessively thick donor button (400 microns), following insertion, which was retamponaded with air, but the graft failed to clear.

The limitations of this study are the inability to assess the effect of precut donor tissue, and the effects of donor dislocation requiring repeat air tamponade on PGF since only one precut donor tissue was used and only two dislocations occurred in this series. However, due to the high rate of PGF (even if this comes under the caveat of the "learning curve") and the increased use of good quality donor tissue, the authors felt it was important to identify any donor or surgical risk factors that may affect early graft survival. Whether these patients will be at increased risk of graft rejection long term, following repeat re-grafting, remains to be seen. Several surgeons have used the surgical learning curve as an acceptable excuse for the high rates of PGF following DSAEK, and often the first 20 cases may be removed before reporting results. In this present study, the first 20 "taco" insertions were examined and compared with the first 20 "glide" insertions, which revealed PGF rates of 25\% (5/20) versus $5 \%(1 / 20)$ respectively. In fact, the center's overall PGF rate to date using the "glide" insertion is currently $0.45 \%(1 / 220)$ (including the first 20 cases). Although the first 20 glide insertions were performed following the first 20 "taco" insertions, with no other changes in the surgical technique, the authors of this paper had the same steep learning curve in terms of donor insertion, minimizing any bias.

Statistical analysis comparing the outcomes between corneas from the same donor, may provide more robust statistical analysis of the data, as well as correlation in outcomes in repeat operations on the same eye, but these were not possible since almost $50 \%$ of the donors came from a foreign source (USA). When contact tracing of the donor mates of these corneas was performed, the authors of this paper were informed that many of the corneas had been used for PK and not DSAEK. Moreover, the small numbers of PGF in this present series limit the statistical power of the results, with wide CIs, albeit statistically significant.

The herpes virus genus has been implicated in one-third of cases as a cause of PGF following PK. ${ }^{23}$ In this series, polymerase chain reaction was not performed on any of the donor tissue, but there was no evidence of lymhocytic infiltration on histology, or presence of viral virions in the stromal keratocytes on electron microscopy, of the removed failed tissue. ${ }^{12}$ Four of the corneas in this present study with PGF were mated. Mated corneas may be more likely to fail as a result of inherent donor endothelial disease or postmortem changes that may affect both eyes. Even though all of the mated corneas had endothelial cell counts greater than 2500 cells $/ \mathrm{mm}^{2}$ and two had counts greater than 2800 cells $/ \mathrm{mm}^{2}$, donor mating may still have an effect.

In summary, endothelial keratoplasty is becoming the procedure of choice for many surgeons in the management of patients with primary (eg, corneal dystrophies) or secondary (bullous keratopathy or graft failure) endothelial failure. The results of this present study implicate that it is surgical trauma relating to the technique of donor insertion and the 
use of a small donor, which appear to be major risk factors for PGF following DSAEK in Asian eyes. This study also supports recent evidence that it may not be justified to request for donors with higher ECD, but instead to choose a better surgical technique to reduce endothelial damage. ${ }^{8}$ If we are to avoid an abundance of graft failures and subsequent increase in demand of good quality donor corneal tissue, ${ }^{24}$ efforts must be made to reduce endothelial cell trauma when performing DSAEK, even in the learning curve period.

\section{Disclosure}

The authors have no financial disclosures or conflict of interests to declare in relation to this paper.

\section{References}

1. Wilhelmus KR, Stulting RD, Sugar J, Khan MM. Primary corneal graft failure. A national reporting system. Medical Advisory Board of the Eye Bank Association of America. Arch Ophthalmol. 1995;113(12):1497-1502.

2. Wilson SE, Kaufman HE. Graft failure after penetrating keratoplasty. Surv Ophthalmol. 1990;34(5):325-356.

3. Buxton JN, Seedor JA, Perry HD, Eagle RC, Pecego JA. Donor failure after corneal transplantation surgery. Cornea. 1988;7(2):89-95.

4. Mead MD, Hyman L, Grimson R, Schein OD. Primary graft failure: a case control investigation of a purported cluster. Cornea. 1994;13(4):310-316.

5. Price MO, Price FW Jr. Descemet's stripping with endothelial keratoplasty: comparative outcomes with microkeratome-dissected and manually dissected donor tissue. Ophthalmology. 2006;113(11):1936-1942.

6. Price FW Jr, Price MO. Descemet's stripping with endothelial keratoplasty in 200 eyes: early challenges and techniques to enhance donor adherence. J Cataract Refract Surg. 2006;32(3):411-418.

7. Lee WB, Jacobs DS, Musch DC, Kaufman SC, Reinhart WJ, Shtein RM. Descemet's stripping endothelial keratoplasty: safety and outcomes: a report by the American Academy of Ophthalmology. Ophthalmology. 2009;116(9):1818-1830.

8. Price MO, Price FW Jr. Endothelial cell loss after descemet stripping with endothelial keratoplasty influencing factors and 2-year trend. Ophthalmology. 2008;115(5):857-865.

9. Mearza AA, Qureshi MA, Rostron CK. Experience and 12-month results of descemet-stripping endothelial keratoplasty (DSEK) with a smallincision technique. Cornea. 2007;26(3):279-283.
10. Mehta JS, PorYM, Beuerman RW, Tan DT. Glide insertion technique for donor cornea lenticule during Descemet's stripping automated endothelial keratoplasty. J Cataract Refract Surg. 2007;33(11):1846-1850.

11. Yuen LH, He M, Aung T, Htoon HM, Tan DT, Mehta JS. Biometry of the cornea and anterior chamber in chinese eyes: an anterior segment optical coherence tomography study. Invest Ophthalmol Vis Sci. 2010;51(7):3433-3440.

12. Mehta JS, Por YM, Poh R, Beuerman RW, Tan D. Comparison of donor insertion techniques for descemet stripping automated endothelial keratoplasty. Arch Ophthalmol. 2008;126(10):1383-1388.

13. Mehta JS, Chua J, Poh R, Beuerman RW, Tan D. Primary graft failure after Descemet-stripping automated endothelial keratoplasty: clinico-pathological study. Cornea. 2008;27(6):722-726.

14. Wang IJ, Hu FR. Effect of shaking of corneal endothelial preservation. Curr Eye Res. 1997;16(11):1111-1118.

15. Terry MA, Shamie N, Chen ES, Hoar KL, Phillips PM, Friend DJ. Endothelial keratoplasty: the influence of preoperative donor endothelial cell densities on dislocation, primary graft failure, and 1-year cell counts. Cornea. 2008;27(10):1131-1137.

16. Price MO, Gorovoy M, Benetz BA, et al. Descemet's stripping automated endothelial keratoplasty outcomes compared with penetrating keratoplasty from the Cornea Donor Study. Ophthalmology. 2010;117(3):438-444.

17. Suh LH, Dawson DG, Mutapcic L, et al. Histopathologic examination of failed grafts in Descemet's stripping with automated endothelial keratoplasty. Ophthalmology. 2009;116(4):603-608.

18. Oster SF, Ebrahimi KB, Eberhart CG, Schein OD, Stark WJ, Jun AS. A clinicopathologic series of primary graft failure after Descemet's stripping and automated endothelial keratoplasty. Ophthalmology. 2009;116(4):609-614.

19. Shih CY, Ritterband DC, Rubino S, et al. Visually significant and nonsignificant complications arising from Descemet stripping automated endothelial keratoplasty. Am J Ophthalmol. 2009;148(6):837-843.

20. Shulman J, Kropinak M, Ritterband DC, et al. Failed descemet-stripping automated endothelial keratoplasty grafts: a clinicopathologic analysis. Am J Ophthalmol. 2009;148(5):752-759. e2.

21. Suh LH, Yoo SH, Deobhakta A, et al. Complications of Descemet's stripping with automated endothelial keratoplasty: survey of 118 eyes at One Institute. Ophthalmology. 2008;115(9):1517-1524.

22. Gorovoy MS. Descemet-stripping automated endothelial keratoplasty. Cornea. 2006;25(8):886-889.

23. Cockerham GC, Bijwaard K, Sheng ZM, Hidayat AA, Font RL, McLean IW. Primary graft failure: a clinicopathologic and molecular analysis. Ophthalmology. 2000;107(11):2083-2090; discussion 2090-2091.

24. Patel SV. Keratoplasty for endothelial dysfunction. Ophthalmology. 2007;114(4):627-628.

\section{Clinical Ophthalmology}

\section{Publish your work in this journal}

Clinical Ophthalmology is an international, peer-reviewed journal covering all subspecialties within ophthalmology. Key topics include: Optometry; Visual science; Pharmacology and drug therapy in eye diseases; Basic Sciences; Primary and Secondary eye care; Patient Safety and Quality of Care Improvements. This journal is indexed on Submit your manuscript here: http://www.dovepress.com/clinical-ophthalmology-journal

\section{Dovepress}

PubMed Central and CAS, and is the official journal of The Society of Clinical Ophthalmology (SCO). The manuscript management system is completely online and includes a very quick and fair peer-review system, which is all easy to use. Visit http://www.dovepress.com/ testimonials.php to read real quotes from published authors. 